\title{
HAEMOGLOBIN LEVELS IN PREMATURE INFANTS
}

\author{
BY \\ MALCOLM ARTHURTON, DONOUGH O'BRIEN and TREVOR MANN \\ From the Institutes of Obstetrics and Child Health, Hammersmith Hospital, London
}

(RECEIVED FOR PUBLICATION JUNE 12, 1953)

Most existing accounts of haemoglobin values in healthy premature infants covering the early weeks of life were written before many of the errors of such determinations were recognized. Because of these limitations it was decided to review the normal values for the first three months of life. The results were compared with a small series of readings made on a group of healthy, full-term infants.

\section{Method of Investigation}

Two hundred blood samples were taken, 185 of these being from a scalp vein, 13 from other veins (external jugular, antecubital or femoral), and in two instances heel-prick specimens were used. About 0.5 $\mathrm{ml}$. of blood was withdrawn into a well-fitting sterile $2 \mathrm{ml}$. all-glass syringe and placed at once in a tube containing a small quantity of dry heparin. After mixing $20 \mathrm{c.mm}$. of blood was pipetted into $4 \mathrm{ml}$. of $0.04 \%$ ammonia solution. The haemoglobin percentage was then read off directly in an 'M.R.C. grey wedge photometer'. In this instrument a scale reading of $100 \%$ is equivalent to $14 \cdot 8 \mathrm{~g}$. $\mathrm{Hb} / 100 \mathrm{ml}$.

All samples were taken and all readings made by the authors and the average of six readings was taken as the final result. The photometer itself was checked at frequent intervals against a grey screen of known density and on three occasions blood samples of known haemoglobin concentration supplied by the M.R.C. Haemoglobin Standards Scheme were tested. Readings made by each of us on these occasions did not vary by more than $0.5 \mathrm{~g}$. $\mathrm{Hb} /$ $100 \mathrm{ml}$. from the expected figure.

During the first part of the study serial haemoglobin estimations were made on 22 healthy premature infants whose birth weights ranged between

TABLE 1

PREMATURE INFANTS

\begin{tabular}{c|c|c|c|c|c}
\hline $\begin{array}{c}\text { Birth Weight Range } \\
\text { (lb./oz.) }\end{array}$ & $1 \cdot 9-2 \cdot 8$ & $2 \cdot 9-3 \cdot 8$ & $3 \cdot 9-4 \cdot 8$ & $4 \cdot 9-5 \cdot 8$ \\
\hline No. of Infants & $\cdots$ & 1 & 8 & 10 & 3 \\
\hline
\end{tabular}

$2 \mathrm{lb} .7 \mathrm{oz}$. and $5 \mathrm{lb} .3 \mathrm{oz}$. Table 1 shows the distribution of cases in four groups according to birth weight.

Six infants were born at home and subsequently admitted to the Premature Baby Unit. Six were the survivors of multiple births. An average of six estimations was made on each infant during the first three months of life, the initial reading being made as soon as the baby's clinical condition was satisfactory.

In the second part of the study a few haemoglobin determinations were made by the same technique on each of 17 healthy full-term infants for comparison with the first series. Table 2 gives the distribution of the cases between four birth-weight groups.

TABLE 2

FULL-TERM INFANTS

\begin{tabular}{|c|c|c|c|c|}
\hline $\begin{array}{c}\text { Birth weight range } \\
\text { (lb./oz.) }\end{array}$ & $5 \cdot 9-6 \cdot 8$ & $6 \cdot 9-7 \cdot 8$ & $7 \cdot 9-8 \cdot 8$ & $8 \cdot 9-9 \cdot 8$ \\
\hline No. of Infants & 3 & 6 & 6 & 2 \\
\hline
\end{tabular}

Two readings were obtained in the Maternity Unit during the first 10 days of life and two further ones were made in the infant follow-up clinic between the fortieth and sixtieth and the eightieth and hundredth days. In two cases a final reading was not obtained.

None of the babies in either group was given iron therapy or a blood transfusion during the period of the investigation. The normal practice in the premature baby unit is to give iron at the age of 6 weeks or on discharge from hospital if this occurs sooner. Breast milk is largely used for feeding in hospital. When artificial feeding becomes necessary Half Cream National Dried Milk, which does not contain added iron, is given. The possibility that some of the babies in the two groups were fed on an iron-fortified proprietary dried milk on returning home cannot be excluded.

\section{Results}

Premature Infants.-Fig. 1 shows the individual readings and the day of life on which they were 


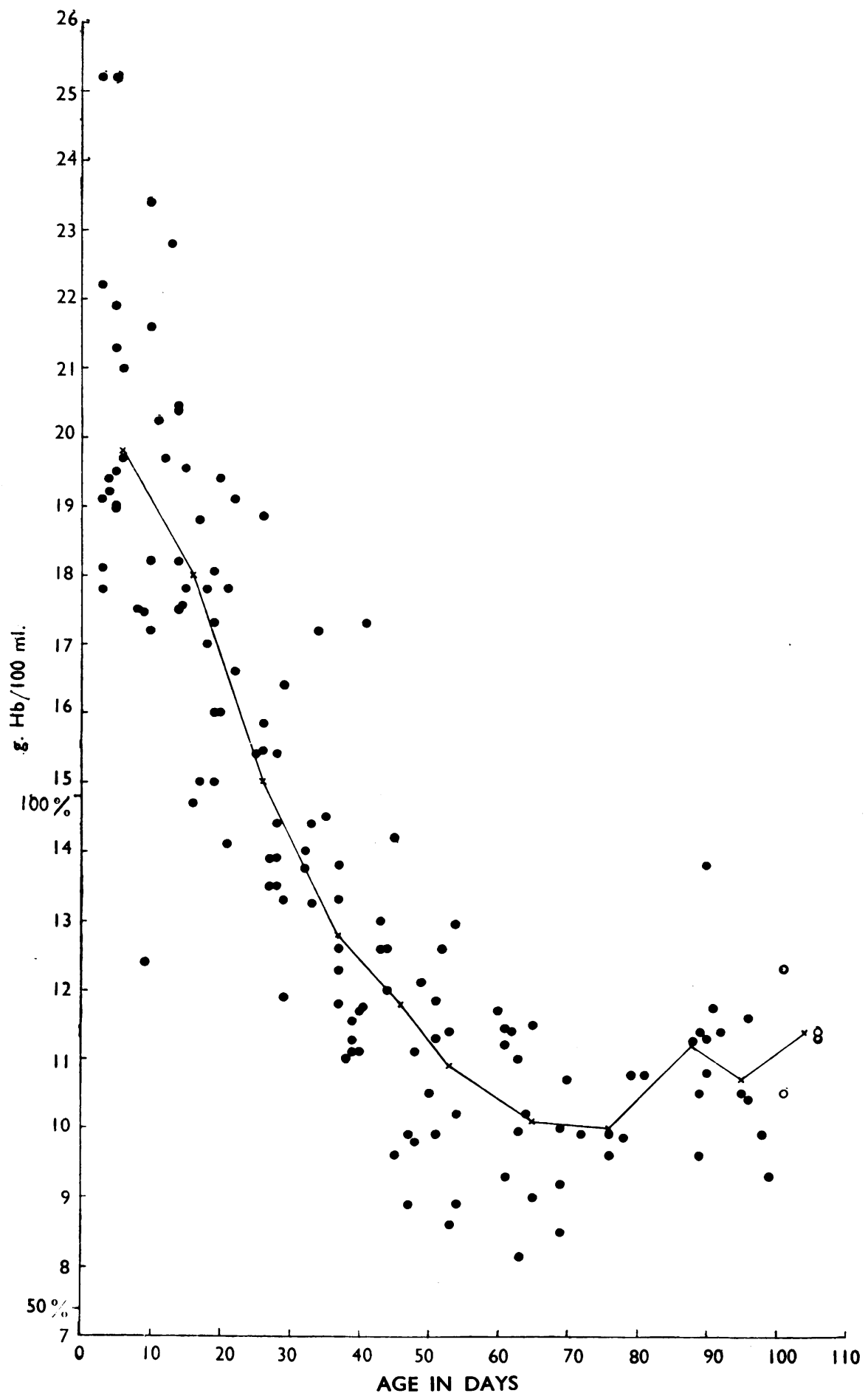

FIG. 1.-Premature infants: individual readings with graph of average values. 


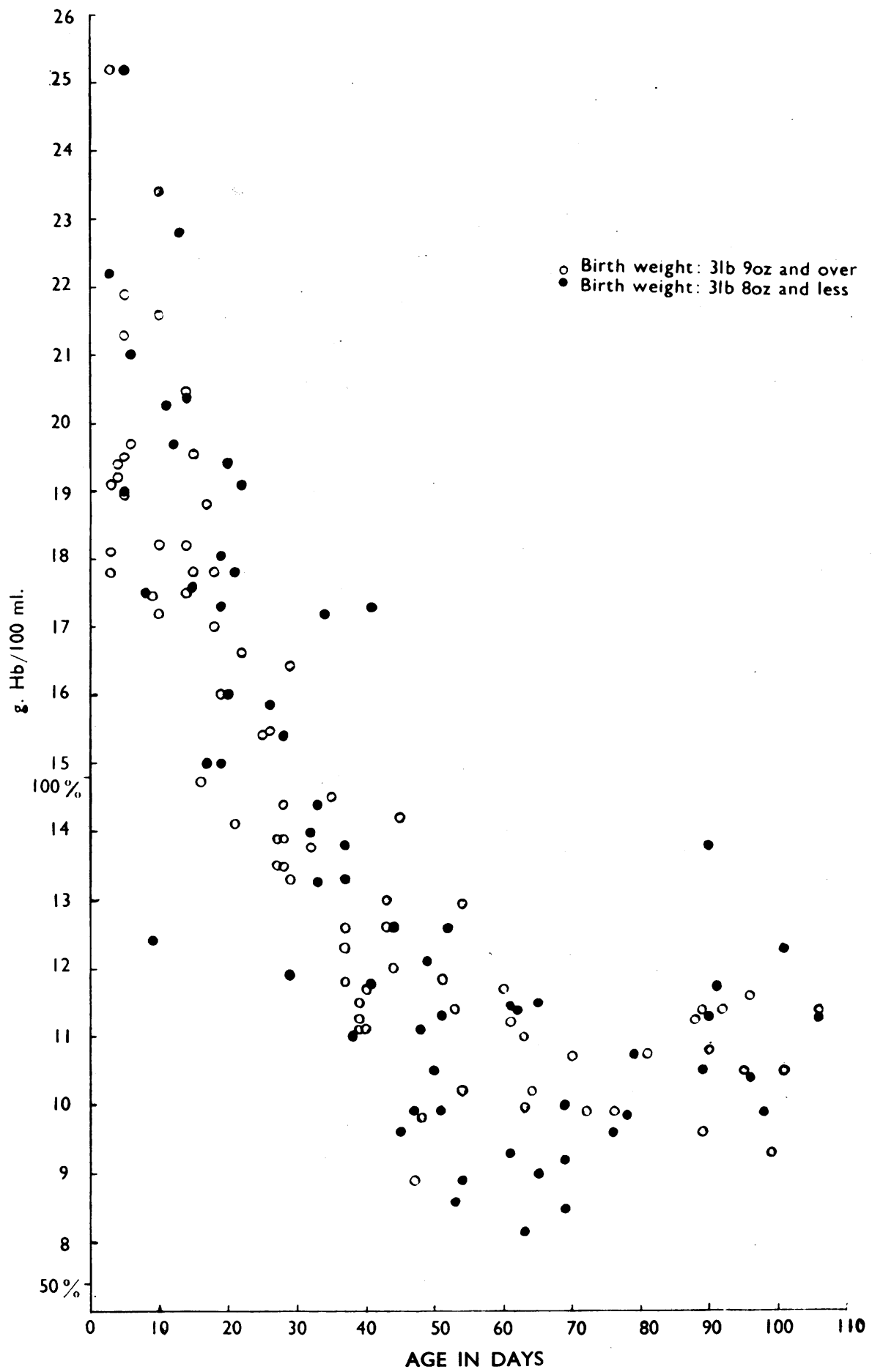

Fig. 2.-Premature infants: comparison of values from those above and below $3 \frac{1}{2} \mathrm{lb}$. birth weight. 
obtained.* The highest initial level was $25 \cdot 2 \mathrm{~g}$. $\mathrm{Hb} / 100 \mathrm{ml}$. recorded on the third and fifth days respectively in two babies. The lowest initial reading was $12 \cdot 4 \mathrm{~g} . \mathrm{Hb} / 100 \mathrm{ml}$. found on the ninth day. The lowest value recorded during the investigation was $8 \cdot 2 \mathrm{~g} . \mathrm{Hb} / 100 \mathrm{ml}$. on the sixty-third day. A consideration of the individual haemoglobin trends showed that there was a tendency for the levels of babies with initial readings above $20 \mathrm{~g}$. $\mathrm{Hb} / 100 \mathrm{ml}$. to fall more than $10 \mathrm{~g} . \mathrm{Hb} / 100 \mathrm{ml}$. and those starting below $20 \mathrm{~g}$. $\mathrm{Hb} / 100 \mathrm{ml}$. to fall less. In two cases it was noted that the haemoglobin concentration rose between the initial readings on the third and fifth days respectively and the second observations on the fourteenth day.

Fig. 1 also shows the averages of all readings made in each 10-day period plotted at points representing the average time at which they were obtained. The curve shows the decline of average haemoglobin values to be maximal between the second and fifth weeks. The fall ceases between the ninth and eleventh weeks and thereafter there is a rise to $11 \cdot 4 \mathrm{~g}$. $\mathrm{Hb} / 100 \mathrm{ml}$. by the fifteenth week. The small rise on the curve just beyond the trough is probably due to the fact that the last four points on the graph are based on small numbers of cases. Although the curve of average values reaches its lowest level of $10 \cdot 1 \mathrm{~g} . \mathrm{Hb} / 100 \mathrm{ml}$. on the seventy-sixth day, there was considerable variation of the time at which individual children reached their lowest reading. Thus in some cases the lowest point of the curve was reached on or before the sixtieth day whereas in others the levels were still falling at that time.

Fig. 2 shows the scatter of readings of premature infants divided into two groups according to whether or not their birth weights exceeded $3 \frac{1}{2} \mathrm{lb}$. The figures for the two groups are well admixed, but of the six values of $9.0 \mathrm{~g}$. $\mathrm{Hb} / 100 \mathrm{ml}$. or less, five were obtained from infants in the lower weight group.

In Fig. 3 the curve of average values in Fig. 1 is compared with average readings obtained in premature infants at different ages by Merritt and Davidson (1934) and by Mackay (1935). It will be seen that our figures correspond very closely with theirs.

Full-Term Infants.-The highest initial level was $22.9 \mathrm{~g} . \mathrm{Hb} / 100 \mathrm{ml}$. on the fourth day. In four babies the haemoglobin concentration rose between the initial readings made on the third or fourth day and those on the ninth or tenth day. The average readings for the full-term series are shown in Table 3 as the

\footnotetext{
*Full results have been deposited with the British Museum (Natura History) Cromwell Road, London, S.W.7, and can be obtained by anyone interested.
}

infrequency of observations does not permit the construction of a graph of any value. Table 3 also shows the average day on which these readings were made and the number of readings upon which the average haemoglobin values are based. The fact that the average level appears to be still falling at the ninety-first day is almost certainly misleading and is probably accounted for by the trough of the curve lying somewhere between the third and fourth readings (i.e. between the forty-seventh and ninety-first days).

TABLE 3

FULL-TERM INFANTS

\begin{tabular}{|c|c|c|c|c|}
\hline Age (in days) & $0-5$ & $6-10$ & $42-52$ & $83-99$ \\
\hline $\begin{array}{c}\text { Average value }(\mathrm{g} . \mathrm{Hb} / \\
100 \mathrm{ml} .)\end{array}$ & $19 \cdot 1$ & $18 \cdot 4$ & $13 \cdot 3$ & $12 \cdot 6$ \\
\hline $\begin{array}{ccc}\text { Average day of read- } \\
\text { ings } & \ldots & .\end{array}$ & $3 \cdot 3$ & $9 \cdot 4$ & 47 & 91 \\
\hline No. of readings & 17 & 16 & 17 & 15 \\
\hline
\end{tabular}

In Table 4 average haemoglobin values for premature and full-term infants are compared at four periods during the first four months of life for which there are an adequate number of readings in each group. During the first two weeks of life the two average values found for the premature group exceed the two corresponding ones for the full-term series by approximately $1.0 \mathrm{~g}$. $\mathrm{Hb} / 100 \mathrm{ml}$., but the difference is not statistically significant. After the sixth week, however, the position is reversed, the two average levels for the full-term babies being between 1.0 and $2.0 \mathrm{~g}$. $\mathrm{Hb} / 100 \mathrm{ml}$. higher than the two corresponding levels for the premature ones-a difference that is now significant.

TABLE 4

VALUES FOR PREMATURES AND FULL-TERM INFANTS COMPARED

\begin{tabular}{c|c|c|c|c|c|c|c|c}
\hline $\begin{array}{c}\text { Time } \\
\text { Period } \\
\text { (inclusive } \\
\text { days) }\end{array}$ & Prem. & F.T. & Prem. & F.T. & Prem. & F.T. & Prem. & F.T. \\
\hline $\begin{array}{c}\text { Average day } \\
\text { of readings . }\end{array}$ & 4 & $3 \cdot 4$ & $9-5$ & $6-13$ & $42-52$ & $42-52$ & $90-100$ & $90-100$ \\
\hline $\begin{array}{c}\text { No. of read- } \\
\text { ings in each } \\
\text { period .. }\end{array}$ & 13 & 16 & 12 & 16 & 16 & 17 & 10 & 9 \\
\hline $\begin{array}{c}\text { Average value } \\
\text { (g. Hb!100 } \\
\text { mi.) }\end{array}$ & 20.4 & $19 \cdot 1$ & $19 \cdot 3$ & 18.4 & 11.4 & 13.3 & $11 \cdot 1$ & 12.6 \\
\hline
\end{tabular}

\section{Discussion}

In recent years there has been an increasing awareness of the instrumental, technical and subjective 


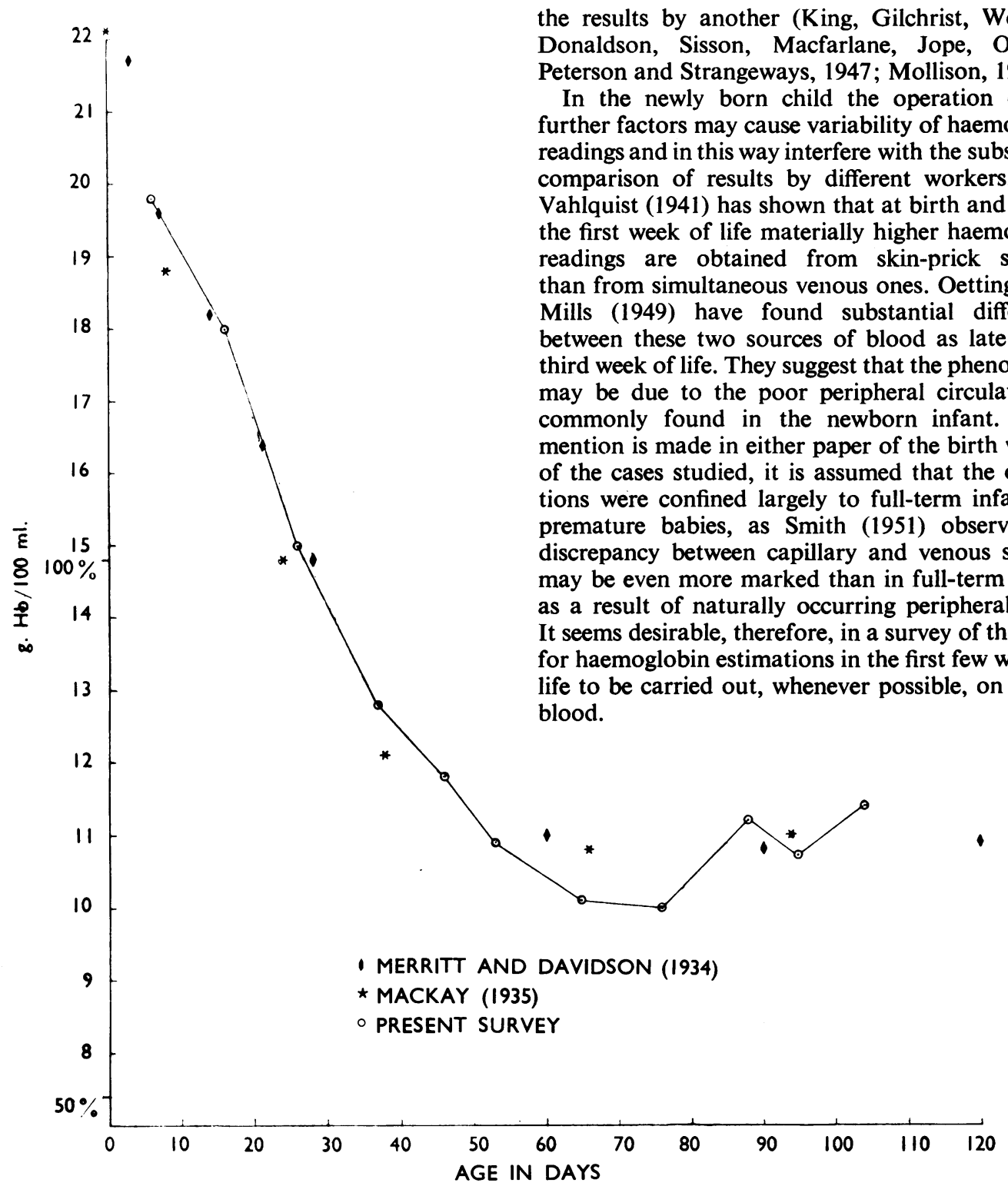

FIG. 3.-Premature infants: average values compared with those of other authors.

factors which may affect the accuracy of haemoglobin estimations. Macfarlane (1945), for instance, enumerates a number of sources of error which may lead to wide differences in the estimates by two or more observers on a divided sample of blood. The importance of accurate haemoglobin standardization has not been generally appreciated in the past and accordingly the results obtained by one method have not always been capable of comparison with
The second factor, and a most important one, is the time when the cord is clamped. It is now well established that the haemoglobin after birth is higher if the cord has been tied late rather than at the moment of birth (DeMarsh, Alt and Windle, 1941), an effect which influences the levels obtained during the first two to three months of life (Johnson, 1948). DeMarsh, Windle and Alt (1942) estimate that the newborn child at term may be deprived of about 
$100 \mathrm{ml}$. of blood if the cord is tied promptly after birth. Such deprivation is probably of greater significance to premature infants, since Barcroft (1946), working with sheep, has shown that the ratio of placental to foetal blood volume decreases as pregnancy advances.

In this survey we have tried to reduce known and avoidable errors. The use of the M.R.C. photometer, as described, has enabled us to express our results in terms of a colour standard established by the National Physical Laboratory, and to eliminate some of the sources of error in colour matching referred to by Macfarlane (1945). Venous blood has been used throughout the investigation, except in two full-term babies. To avoid errors resulting from excessive venous congestion (M.R.C. Report, 1945) manual constriction of the scalp was applied only just before sampling. Unfortunately, it has not been possible to control satisfactorily the time of cord ligation in this study. The practice at Hammersmith Hospital of tying it a few minutes and not immediately after birth in both full-term and premature babies probably represents conditions as they occur in most domiciliary and hospital deliveries.

A comparison of our cases after dividing them into two groups according to whether or not their birth weight exceeds $3 \frac{1}{2} \mathrm{lb}$. is of some interest. Blackfan and Diamond (1944) have shown in a group of 75 prematurely born infants that the more premature the baby and the less the birth weight the more severe is the physiological anaemia. Comparing our two groups we find that although the smaller infants tend to reach a lower haemoglobin level between the eighth and twelfth weeks of life than the larger ones, the individual readings for the two groups are well admixed in each 10-day period and the difference is not as striking as had been anticipated.

Our findings suggest that blood transfusion has little place in the care of healthy premature infants. Before this survey it had not been considered necessary to transfuse any of 521 normal babies admitted to the Premature Baby Unit. A haemoglobin reading was carried out on each case as a routine just before discharge, unless unusual pallor demanded an earlier estimation. Each child was sent home on an iron mixture and its general condition checked periodically in a special follow-up clinic until the first birthday had been passed.

Iron deficiency anaemia which may appear during the second six months of life did not constitute a problem when this routine was followed. Transfusion would, of course, have been considered in the early months if the haemoglobin concentration had fallen below $8 \cdot 0 \mathrm{~g} . \mathrm{Hb} / 100 \mathrm{ml}$. or remained at that level for a week or two. Unlike Rossier and Potiron (1952) we do not favour the use of small repeated transfusions as a routine in all premature infants. Although these workers report only six non-fatal reactions in over 1,000 transfusions, we still do not think it justifiable to expose a premature baby unnecessarily to the possible hazards of a procedure which may only serve to inhibit erythropoiesis at a time when marrow activity is on the point of revival and which, furthermore, may increase the possibility of transfusion reactions in later life.

\section{Summary}

A study has been made of the trend of haemoglobin concentrations during the first three months of life in 22 healthy premature infants.

All estimations have been made with an M.R.C. photometer on venous samples.

Some possible sources of error are discussed.

The results are compared with readings obtained from 17 healthy full-term infants and with those of some other workers.

Some comments are made on the place of blood transfusion in the treatment of the early anaemia of prematurity.

Our thanks are due to Professor Alan Moncrieff for permission to investigate infants under his care, to Drs. P. L. Mollison and Cedric Carter for their constant help and advice, and to Sister M. Smith who assisted with the blood sampling.

\section{REFERENCES}

Barcroft, J. (1946). Researches on Pre-natal Life. 1st ed., vol. 1., p. 67. Oxford.

Blackfan, K. D. and Diamond, L. K. (1944). Atlas of the Blond in Children, 1st ed., p. 26. Commonwealth Fund, New York.

DeMarsh, Q. B., Alt, H. L. and Windle, W. F. (1941). J. Amer. med. Ass., 116, 2568.

Windle, W. F. and Alt, H. L. (1942). Amer. J. Dis. Child. 63, 1123 .

Johnson, A. R. (1948) cited by Dunham, E. C. (1948). Premature Infants. Children's Bureau Publ. No. 325, pp. 298-299. U.S. Federal Security Agency.

King. E. J., Gilchrist, M., Wootton, I. D. P., Donaldson, R., Sisson, R. B., Macfarlane, R. G., Jope, H.'M., O'Brien, J. R. P., Peterson, J. M. and Strangeways, D. H. (1947). Lancet, 2, 789.

Macfarlane, R. G. (1945). Spec. Rep. Ser. med. Res. Coun. Lond. No. 252 , p. 59 .

Mackay, H. M. M. (1935). Archives of Disease in Childhood, 10, 195. Medical Research Council (1945). Spec. Rep. Ser. med. Res. Coun. Lond., No. 252, p. 85.

Merritt, K. K. and Davidson, L. T. (1934). Amer. J. Dis. Child., 47 261.

Mollison, P. L. (1951). Blood Transfusion in Clinical Medicine, 1st ed., p. 348. Oxford

Oettinger, L. and Mills, W. B. (1949). J. Pediat., 35, 362

Rossier, A. and Potiron, L. (1952). Arch. franc. Pédiat.. 9, 113.

Smith, C. A. (1951). The Physiology of the Newborn Infant, 2 nd ed. p. 120. Oxford.

Vahlquist, B. C. (1941). Acta paediat., 28, Suppl. 5, 219. 